\begin{tabular}{|c|c|c|c|}
\hline Article Info & RESEARCH ARTICLE & ARAŞTIRMA MAKALESİ & \\
\hline Title of Article & \multicolumn{2}{|c|}{$\begin{array}{l}\text { Study of Physical and Functional Structure in } \\
\text { Navona Square in Historical Periods }\end{array}$} & \\
\hline $\begin{array}{l}\text { Corresponding } \\
\text { Author }\end{array}$ & \multicolumn{2}{|c|}{$\begin{array}{l}\text { Ziba SAMI } \\
\text { Yildız Teknik university, Architecture and design department, ziba.sami@std.yildiz.edu.tr }\end{array}$} & \\
\hline $\begin{array}{l}\text { Received Date } \\
\text { Accepted Date }\end{array}$ & \multicolumn{2}{|l|}{$\begin{array}{r}27.01 .2020 \\
17.03 .2020\end{array}$} & \\
\hline Author / Authors & $\begin{array}{l}\text { Ziba SAMİ } \\
\text { Merve BİLGEN } \\
\text { Doç. Dr. Ebru ERDÖNMEZ }\end{array}$ & $\begin{array}{l}\text { ORCID: } 0000-0003-0861-8510 \\
\text { ORCID: } 0000-0001-7832-6527 \\
\text { ORCID: } 0000-0001-8779-6037\end{array}$ & \\
\hline How to Cite & \multicolumn{2}{|c|}{$\begin{array}{l}\text { SAMİ, Z., BİLGEN,M., ERDÖNMEZ, E., (2020). Navona Meydanı’nın Tarihsel Süreç } \\
\text { İçerisinde Fiziksel ve İşlevsel Özelliklerinin İncelenmesi, Kent Akademisi, Volume, } 11 \\
\text { (41), Issue 1, Pages; 112-122 }\end{array}$} & $\begin{array}{l}\text { Kent Akademisi } \\
\text { Urban Academy }\end{array}$ \\
\hline
\end{tabular}

\title{
Navona Meydanının Tarihsel Süreç İçerisinde Fiziksel ve İşlevsel Özelliklerinin İncelenmesi
}

ÖZ:

İtalya'nın Orta Çağ Dönemi Meydanları geçmişten günümüze ulaşan önemli meydan örneklerini oluşturmaktadır. Bu çalışmada, Orta Çağ Dönemi Meydanı olan Navona Meydanı’nın tarihsel süreç içerisindeki değişimi ve günümüzdeki fiziksel ve işlevsel özellikleri kalite parametreleri kullanılarak incelenmiştir. Navona Meydanı'nın konumlandığı alan geçmişte stadyum, pazar alanı vb. fonksiyonları barındıran bir kullanıma sahipken 15. yüzyıldan itibaren ' meydan', olarak kullanılmış ve süreç içerisinde dönüşümler geçirmiştir. Bu bağlamda makale, tarihsel süreç içerisinde meydanın geçirdiği değişimlerin, farklı dönemlerde meydana eklemlenen yapıların, Navona Meydanı'nı fiziksel ve işlevsel açıdan nasıl biçimlendirdiği ve mekânsal kalitesini nasıl etkilediğini incelemiştir. Çalışmada ilk olarak meydanın tarihçesi hakkında genel bilgiler araştırılmış olup daha sonra meydanın fiziksel ve işlevsel özellikleri: ' 'konum ve bağlantı', ',erişim- ulaşılabilirlik', ' 'meydanın çevresindeki yapılar', '’meydanın biçimsel özellikleri', ' 'mimari malzeme seçimi', ve meydandaki 'sembol öğeler', başlıkları altında incelenmiştir. Sonuç olarak Navona Meydanı'nın tarihsel süreç içerisinde geçirdiği değişim ve dönüşümlere rağmen fiziksel ve işlevsel sürekliliği sağladığı ve meydanın genel özelliklerinin korunduğu görüşü ortaya konmuştur. Çalışma ile ülkemiz literatürüne katkı sağlamak amaçlanmıştır.

Anahtar Kelimeler:Meydan, Navona, Tarihsel, Fiziksel, işlevi

${ }^{1}$ Yıldız Teknik university, Architecture and design department, ziba.sami@std.yildiz.edu.tr

${ }^{2}$ Y 1 ldız Teknik university, Architecture and design department, bilgenmerve3@gmail.com

${ }^{3}$ Yıldız Teknik university / Architecture Faculties, Architecture department, ebruerdonmez@yahoo.com 


\begin{abstract}
:
Italy's Medieval Period Squares are examples of important squares that have survived from the past to the present. In this study, Navona Square, which is a medieval square, has been examined by using quality parameters. While in the past the area where the Navona Square was had been used for stadium, market etc. functions, from the 15th century onwards it had been used as a "square" and has undergone changes over time. In light of this, the article how the changes in the historical process, the structures articulated in different periods, the functional and physical shape of the square and how this affects its spatial quality. In this study, firstly general information about the history of the square was investigated and then physical and functional properties of the square were investigated under: location and connection, accessibility, structures around the square, formal features of the square, architectural material selection and symbol elements in the square. The results of the study; despite the changes and transformations in Navona Square in the historical process, it has been demonstrated that it provides physical and functional continuity and the general characteristics of the square are preserved. The aim of this study is to contribute to the literature of our country.
\end{abstract}

KEYWORDS: Square, Navona, Historical, Physical, Functional

\title{
GíRiş:
}

Kentler, birçok bileşen ile bağlantılı olarak üreten, değişen ve dönüşen organik bir canlı olarak kabul edilmektedir. Bu sebeple her kent tarihsel izlere dayanan bir kent kimliğine sahiptir. Kent meydanları ise kentsel kimliğin yansıdığı aktif ve dinamik mekânlardır (Kwon, 2016: 83). Kent meydanları, kentlerin tarihsel kolektif bellekleri içerisinde ayrıcalıklı düşünülen uzamsal birliktelikler ya da ayrışmalara ev sahipliği yapması bakımından önemlidir (Keskin, 2018: 343).

Tarihsel süreç içerisinde meydanların gelişimiincelendiğinde, ilk dönemlerde törenlerin, dini aktivitelerin yapıldığı ve sembolik anlamların yüklenmiş olduğu toplanma mekânları iken; modern kentin gelişmesiyle ve kentteki değişimlerle birlikte meydanların fiziksel ve işlevsel özellikleri de değişmiştir (Şahin, 2018:19). Genellikle Roma meydanları en ve boy oranının birbirine yakın olduğu önceden tasarlanmış bir forma sahip iken Sala'ya göre "Roma Kenti'ndeki Navona Meydanı, eninin geniş oluşuyla bu genellemenin dışında kalır. Bunun nedeni meydanın bir Roma forumu üzerinde kurulmuş olmasıdır” (Sala, 2009). Roma'daki Navona Meydanı, kent için önemli bir çekirdek rol oynamış ve kentteki diğer meydanlardan daha farklı işlevler yüklenmiştir (Kwon, 2016: 83). Bu bağlamda çalışmanın amacı Navona Meydanı'nın sahip olduğu fiziksel ve işlevsel kalite parametrelerini analiz ederek incelemektir. Bu doğrultudaçalışmanın devamında önce yerli ve yabancı literatürde"meydan" kavramı ve Roma Meydanları araştırılmış olup sonrasında Navona Meydanı'nın sahip olduğu fiziksel ve işlevsel özellikler fotoğraf, çizim, belge ve analizlerle çalışmaya aktarılarak incelenmiştir.

Şekil 1. Çalışmanınilerleyiş adımları

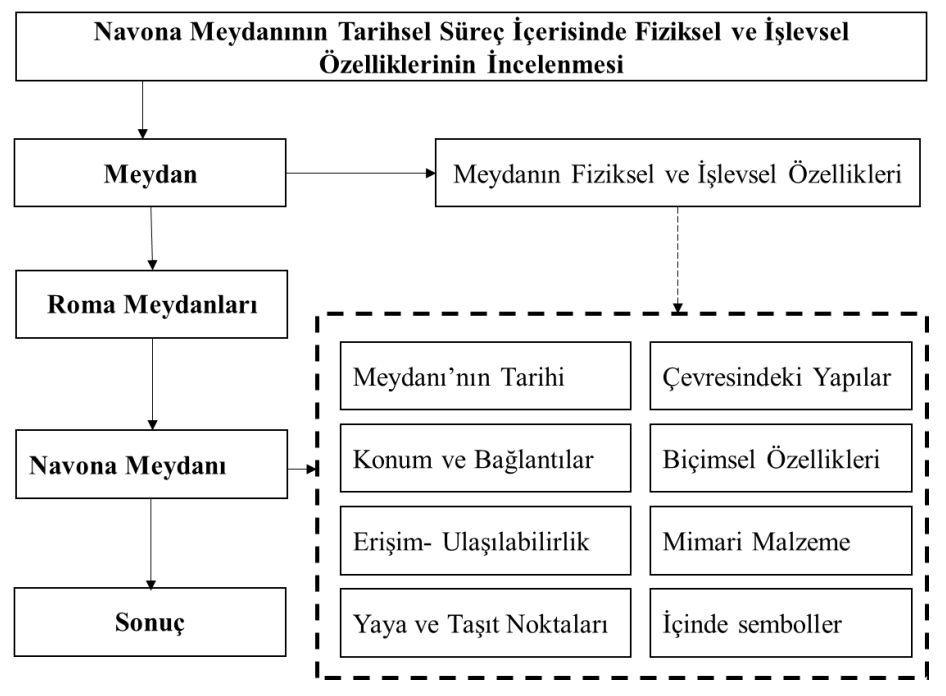




\section{Meydan}

Türkçeye Arapçadan giren 'meydan" kelimesi ' Güncel Türkçe Sözlükte”; alan, saha, yarışma, eğlence ve karşılama yeri, bulunulan yer ve çevresi, ortalık, firsat, imkân veya vakit, Mevlevi Tekkeleri'nde ayin yapılan yer olarak tanımlanmıştır (Şahin, 2018:18). İspanyolca 'da "plaza" İtalyanca 'da "piazza" kelimelerine karşlık gelen meydan, Latincede açık mekân veya genişletilmiş sokak anlamına gelen "platea" kelimesinden türetilmiştir. Meydan, İngilizcede aynı zamanda kare anlamına gelen "square" kelimesinin de karşılığı olan sınırları yapılarla belirlenmiş, tanımlı mekânlar için kullanılmaktadır (Eyüce, 2000:10-11).Meydanlar tarihsel süreçte farklı fonksiyonlar barındırıyor olsa da her dönemde kent yaşamının önemli bir parçası olmuştur (Taşçı,2012: 75) Hoşkara göre: "Kent mekânları özellikle de "meydanlar", tarihi yerleşmeler içinde, çok çeşitli işlevleri barındırmak üzere gelişmişlerdir" (Hoşkara, 2007: 218). "Meydanlarda büyüklük, form ve fonksiyon açısından sonsuz varyasyonlar oluşturmak mümkündür. Günümüz kentlerinde; kamusal binaların çevresi, buluşma yerleri, gösteriler için toplanma mekânları, tiyatro, sinema, restoran, kafe vb. yerler, alış-veriş yapılan sokaklar, ofis gruplarının yer aldığı çevreler, konut alanlarında yer alan yarı özel mekânlar, trafik kavşakları ve daha pek çok dış mekânlara gereksinim vardır" (Erdönmez ve Abay, 2018: 46). Kamusal alan olarak meydanlar, tarih sürecinde farklı şekillerde oluşmuş veya inşa edilmiştir.

\subsection{Meydanın Fiziksel ve İşlevsel Özellikleri}

Çalışmada Navona Meydanı'nın fiziksel ve İşlevsel kalite ölçütleri şu şekilde incelenmiştir:

\section{Şekil 2. Meydanın Fiziksel ve İşlevsel Özellikleri}

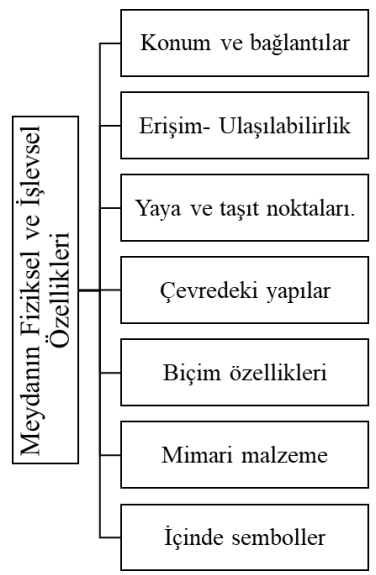

\section{Roma Meydanları}

Roma döneminde mekânın ve binaların geometrisi beden hareketlerini disipline etmek için kullanılmaktadır (Sennett, 2011: 99). Eski Roma forumu (Forum Romanum) siyaset, ekonomi, din ve dostane sohbetlerin iç içe geçtiği Perikles Dönemi'nin Atina agorasına çok benzeyen bir kent merkeziydi. Forumun agoradan farkı, çeşitli kalabalığı dört yanı binalarla çevrili dikdörtgen bir alanın içine almasıdır. Roma forumunda bazilika ve peristil denilen bina formları yapılmışıır. Bu binalardan peristil merkezi bir avlunun ya da binaların etrafından dolanan uzun dizili sütunlardır (Sennett, 2011:97). Roma döneminde (16.yüzyıl) meydanlarda bulunan dikili taşlar Papa'nın etkisiyle dini otoritenin göstergesi olmuştur. Mussolini de 20.yüzyılda aynı obeliskleri meydanlarda siyasi otoritesini simgelemek için kullanmıştır. Günümüzde de benzer biçimde içinde bulunulan dönemi temsil eden bu tür kentsel öğeler, dini, idari ve politik güç gösterilerinin simgeleri olarak kentlerde farklı biçimlerle ve kimliklerle görülmeye devam etmektedir. Günümüzde gelişen ulaşım sistemleri, yoğun iş yaşamı ve beraberinde yoğun araç trafiğinden dolayı kent içinde sıkışan meydanlar, "işlevlerini yeterince yerine getirememekte, kimlik oluşumu, dolayısıyla simgesel zenginlik kazanımı, kentsel mekânda kaygı yaratan bir boyut olarak gelişmiş ülkelerde bile karşımıza çıkmaktadır' (Çınarı, 2004:117-118).

\section{Navona Meydanı}

Günümüzde "Navona" olarak adlandırılan meydanın etimolojisi "Avone", "Navone" ve "Navona" olarak süreç içerisinde değişmiştir (Kwon, 2016:85). Navona Meydanı'nın bulunduğu alan Antik Roma Dönemi'nden M.Ö. 86'ya 
kadar arena olarak kullanılmıș ve 15. yüzyılda halka açık bir pazar yeri ve oyun alanı olarak ișlevlendirilmiștir. Barok Dönem de ise, Roma festivallerinin yapıldığı ve Roma gezginleri için rahat hareket edilen bir yer haline gelmiştir (Knirsch, 2004:16-17).

Şekil 3.Navona Meydanı'nın Tarihsel Süreçteki Gelişimi

$1 \mathrm{y} \cdot \mathrm{y}$

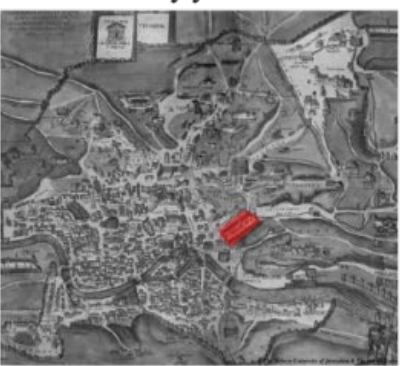

https://firstdrop.nl

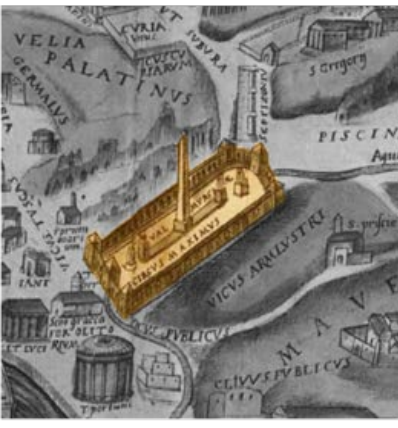

https://mapcollection.wordpress.com
3 y.y

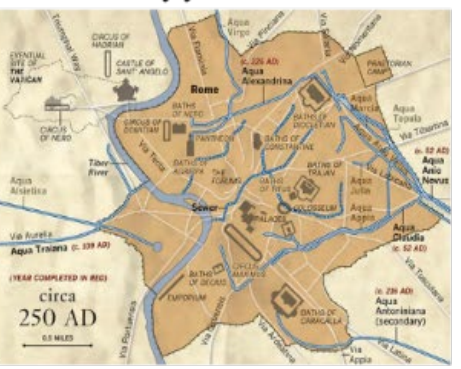

https://firstdrop.nl

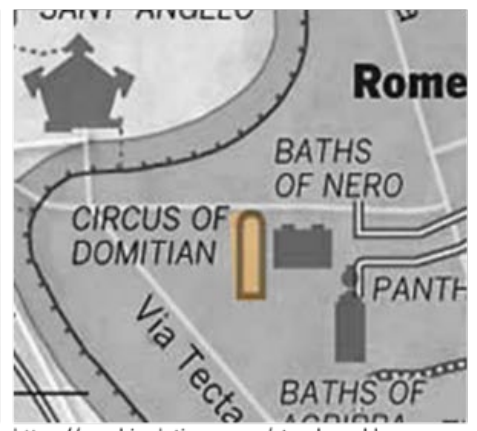

https://graphics.latimes.com/storyboard-lafg-roman-aqueducts-g/
18 y.y

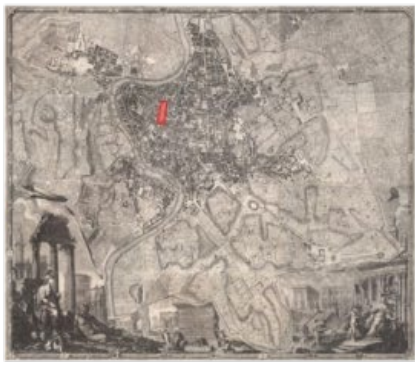

http://nolli.uoregon.edu/letarouilly.htm

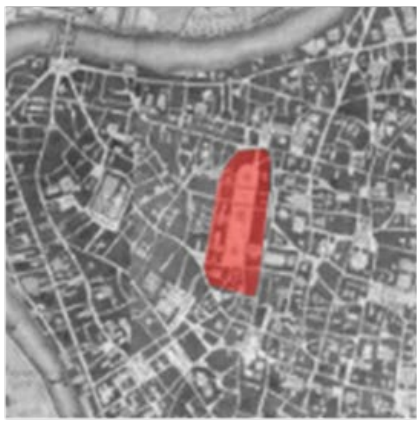

http://www.myestuff.com/authentic-modelsgiclee-wall-map-rome-from-1676-mc808/

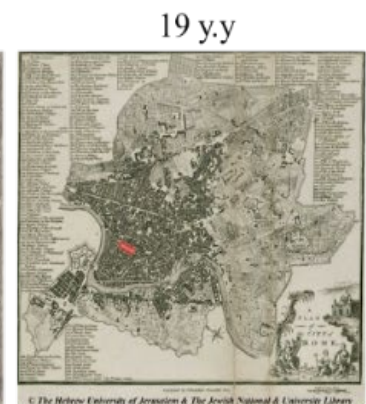

https://www.art.com/products/p426 91422426-sa-i10121018/

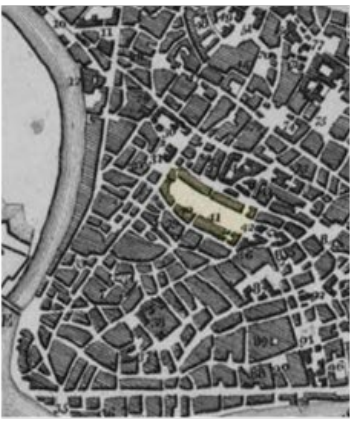

https://www.art.com/products/p426 91422426-sa-i10121018/

Ticaretin, kamusal alanla ve meydanla kurduğu ilişki tarihin erken dönemlerine kadar uzanmaktadır. Agora'dan başlayan bu ilişki, Orta Çağ Dönemi'nde de devam etmiş ve meydan-ticaret ilişkisi açısından en iyi dönemlerini yaşamışıtır (Şahin, 2018:1). Stadyum, 1450 yılına kadar turnuva yeri olmuştur. 1645'te ise Papa tarafından alanın dönüşümü başlatılmıştır (Knirsch, 2004: 5).

Şekil 4.Navona Meydanı M.S. 90 ve Günümüz ${ }^{1}$
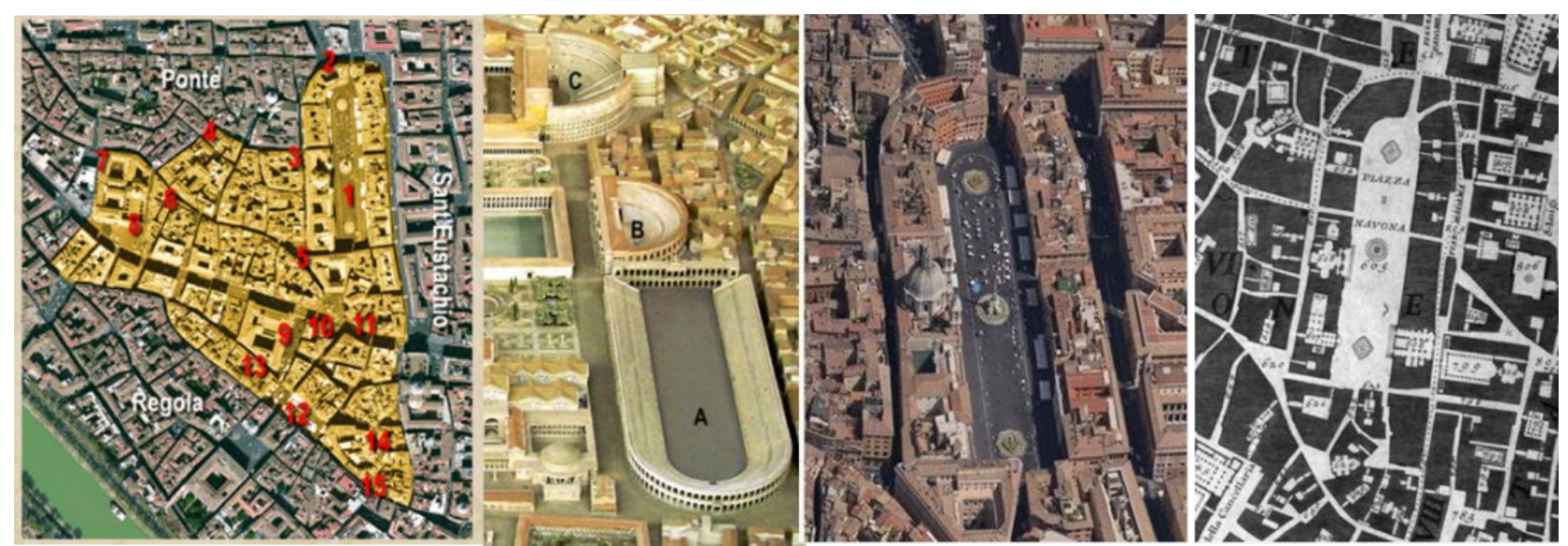

${ }^{1}$ www.colosseumrometickets.com, Bultrini ve Stemperini, 2009: 182 


\subsection{Navona Meydanı'nın Tarihi}

Piazza Navona, ölçülerini ve formunu; ilki Cesar ve Agustus tarafindan ahșaptan yaptırılmış olan, M.S 86'da ise Domitian tarafından spor müsabakaları ve at yarışları için yeniden inşa edilmiş olan 30.000 kişi kapasiteli Circus Agonalis (yarışma alanı) adı ile anılan stadyumdan almaktadır(Yıldırım,2004: 45).3. yüzyılda Colleseum'u tamamen tahrip eden büyük bir yangından sonra, Domitian Stadyumu belli bir süre için amfi tiyatro olarak kullanılmıştır. 4. Yüzyılda ise İmparator Maxentius tarafından ise yarış alanı olarak kullanılmıştır. 1250 yılında stadyumdan geriye kalan meydanda asillerin evleri inșa edilmiștir.Tarihçilere göre, $1450^{\prime}$ de meydanda hala eski stadyumun seyirci basamakları bulunmaktadır(Şekil 5). Papa, 1477'de Kardinal Estouteville'in sahibi olduğu pazarın, Campidoglio'dan buraya taşınmasını sağlayarak alanın Roma için yaşanan popüler bir yere dönüşümünü gerçekleşmiştir(Yıldırım,2004: 46-49).

Şekil 5. Seyirci basamaklar1 ${ }^{1}$ ve Stadyum ve Çevresi (1474), "Agoni Capitolini" (1582-1599), (Camargo, 1981:7-8)
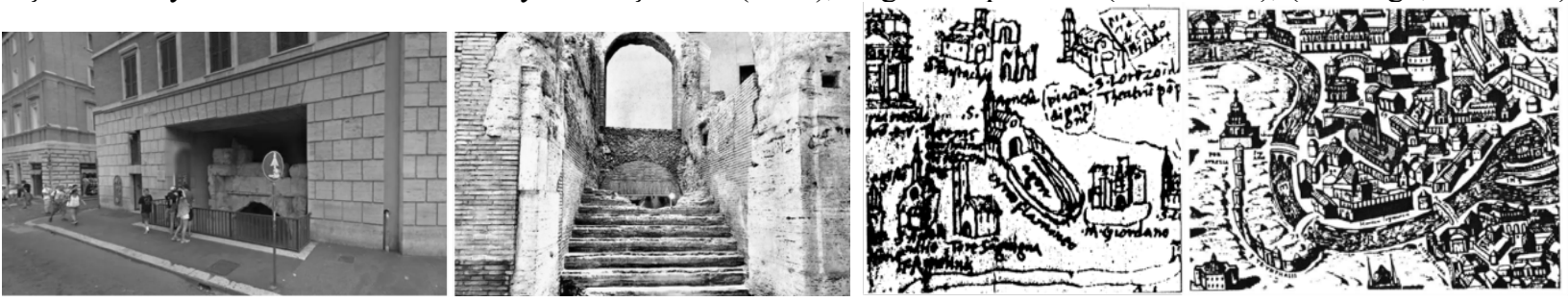

15.yüzyıl'da ise meydana 'San Giacomo degli Spagnoli Kilisesi” yaptırılmıştır.16.yüzyılın sonlarında, Gregory XIII, meydanın iki ucuna G. Della Porta'nın eseri olan birer fıskiyeli süs havuzu, ortasına ise çeşme görevi gören bir yapı yaptırmıştır. 1644'de Papa olarak seçilen Innocent X, meydan için düzenleme faaliyetleri başlatarak G. L Bernini, F Borromini, G. Rainaldi ve P. da Cortona'yı görevlendirmiştir. Bu dönemde inşa edilen Bernini'nin ''Fontana dei Fiumi" havuzu/çeşmesi ve Borromini, Rainaldi ve Cortona'nın tasarımı olan 'Sante Agnese Kilisesi'" Navona Meydanının önemli yapıları arasındadır. Bernini'nin tasarladığı Fontana dei Fiumi²havuzunun suyu, 17. ve 19. yüzyıllar arasında, insanların eğlenceleri ve asillerin arabalarının atlarının ferahlamaları için yaz boyunca her hafta sonu alana kurulan yapay bir göl için kullanılmıştır. Meydanda bulunan üç süs havuzu, obelisk, Sante Agnese Kilisesi'nden başka Papa'nın ailesi için yaptırılmıșen son saray yapısı olan Palazzo Braschi bulunmaktadır. 19.yüzyılda içişleri bakanlığı olarak kullanılmış olan yapı 1930' da faşist federasyon yönetime el koyduktan sonra müze haline getirilmiştir (Yıldırım,2004: 51).

Şekil 6. Navona Meydanı'nın Tarihi Gelişim Zaman Çizelgesi

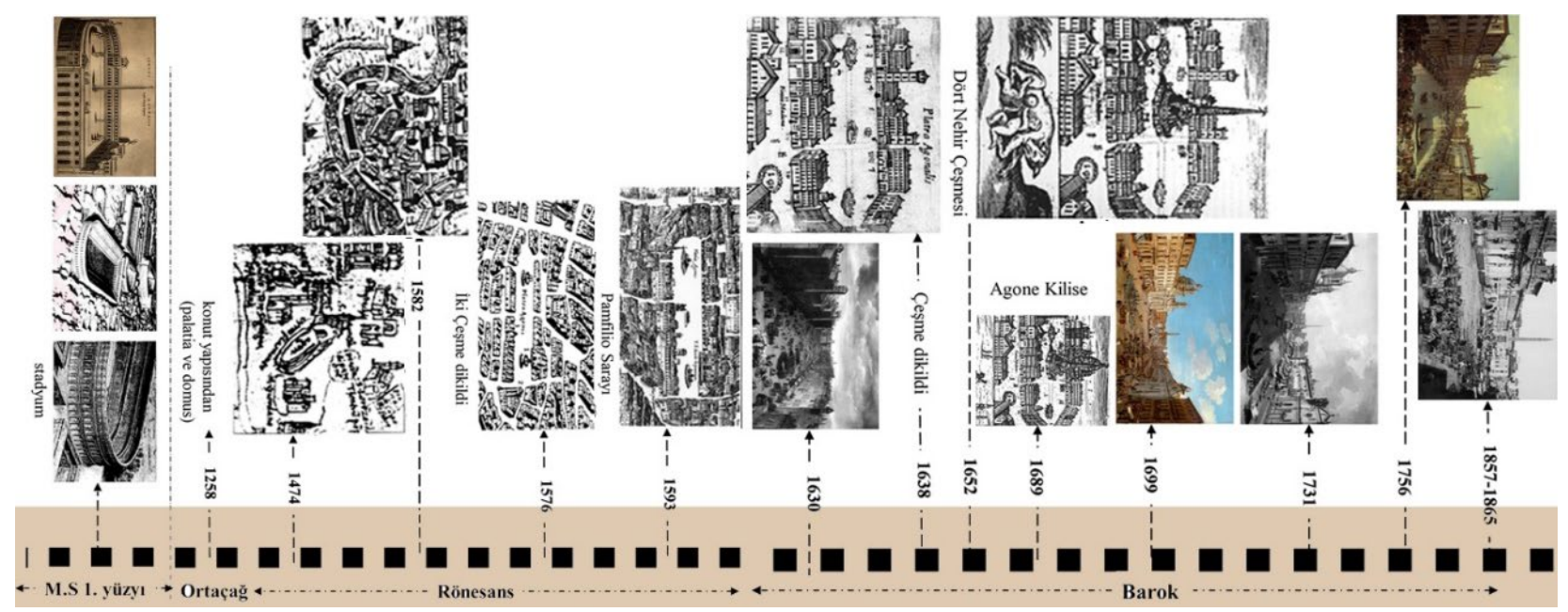

\subsection{Navona Meydanı'nı Konum ve Bağlantılar}

Navona Meydanı Roma'nın tarihi bölgesinde yer almaktadır. Kentin merkezinde konumlanan Navona Meydanı pek çok önemli merkeze ve meydana kolaylıkla erişim mesafesindedir. San Pietro Meydanı'nın uzaklığı yaklaşık 530

$1_{\text {Www.colosseumrometickets.com }}$

${ }^{2}$ Fontain of the Four Rivers 
metre, Popolo Meydanı'nın uzaklığı yaklaşık 215 metre ve Campidoglio Meydan'ı yaklaşık 420 metre uzaklıktadır. Diğer meydanların yeşil dokusuyla olan ilişkisinin aksine Navona Meydan'ı yoğun kentsel doku da ortaya çıkan güçlü bir meydandır (Kwon, 2016:87). Kapalı (arkadlar) ve açık (sokak ve caddeler) kanal mekânlarla kente bağlanmaktadır.

Şekil 7. Navona Meydanı'nınKonumu (http://roma.andreapollett.com)
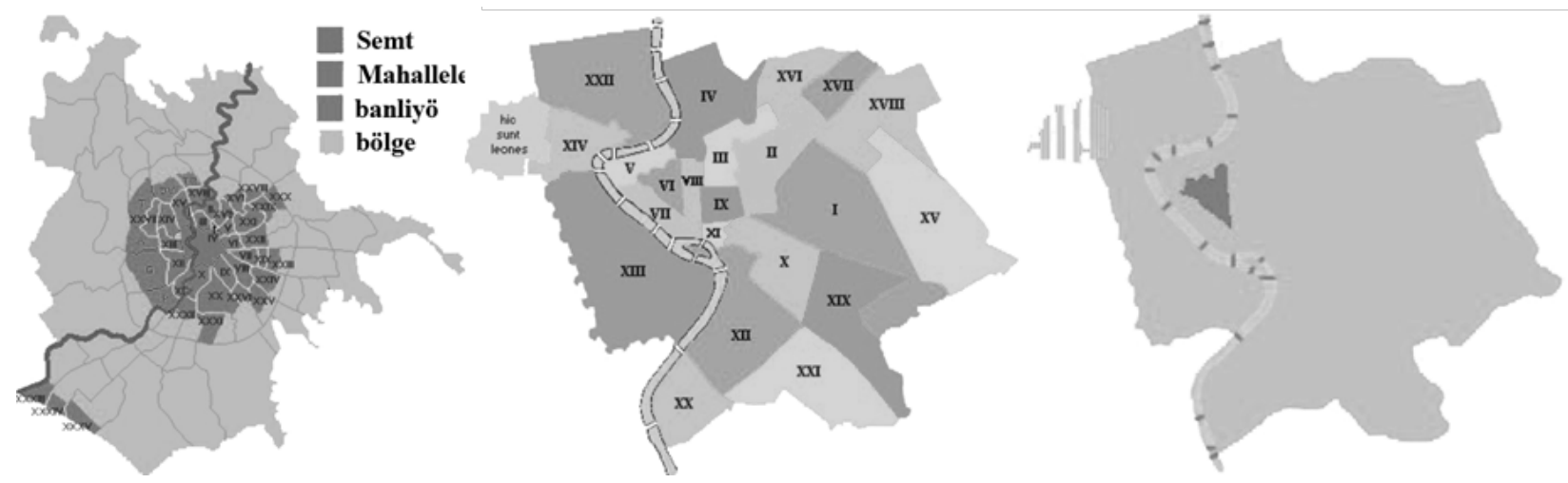

\subsection{Navona Meydanı'nda Erişim- Ulaşılabilirlik}

Yoğun kentsel dokunun içerisinde yer alan Navona Meydanı'nda yaya kullanımı yüksektir. Etrafında yeme-içme mekânlarının bulunması, tarihi yapıların yer alması vb. çekim merkezlerinin çokluğu; Navona Meydanı'nı yoğun bir kitlenin kullanmasına sebep olmaktadır. Navona meydanına erişim yaya, araç ve toplu taşıma ile sağlanabilmektedir. Metro istasyonları yaklaşı $1,5 \mathrm{~km}$ uzaklıkta iken meydanın hemen bitişiğinde yer alan otobüs durakları, bisiklet parkları ve yaya erişimine izin veren sokak ağları ile Navona Meydanı'na erişim kolay ve keyifli hale gelmektedir. Öyle ki meydanın sahip olduğu düz ve eğimsiz topoğrafya, yüksek kaldırımların olmayışı vb. unsurlar fiziksel engelli ziyaretçilerinde meydana kolaylıkla erişimini sağlamaktadır (Özcan, 2009, 249).

Şekil 8. Navona Meydanı'nın Çevresindeki Sokak Dokusu
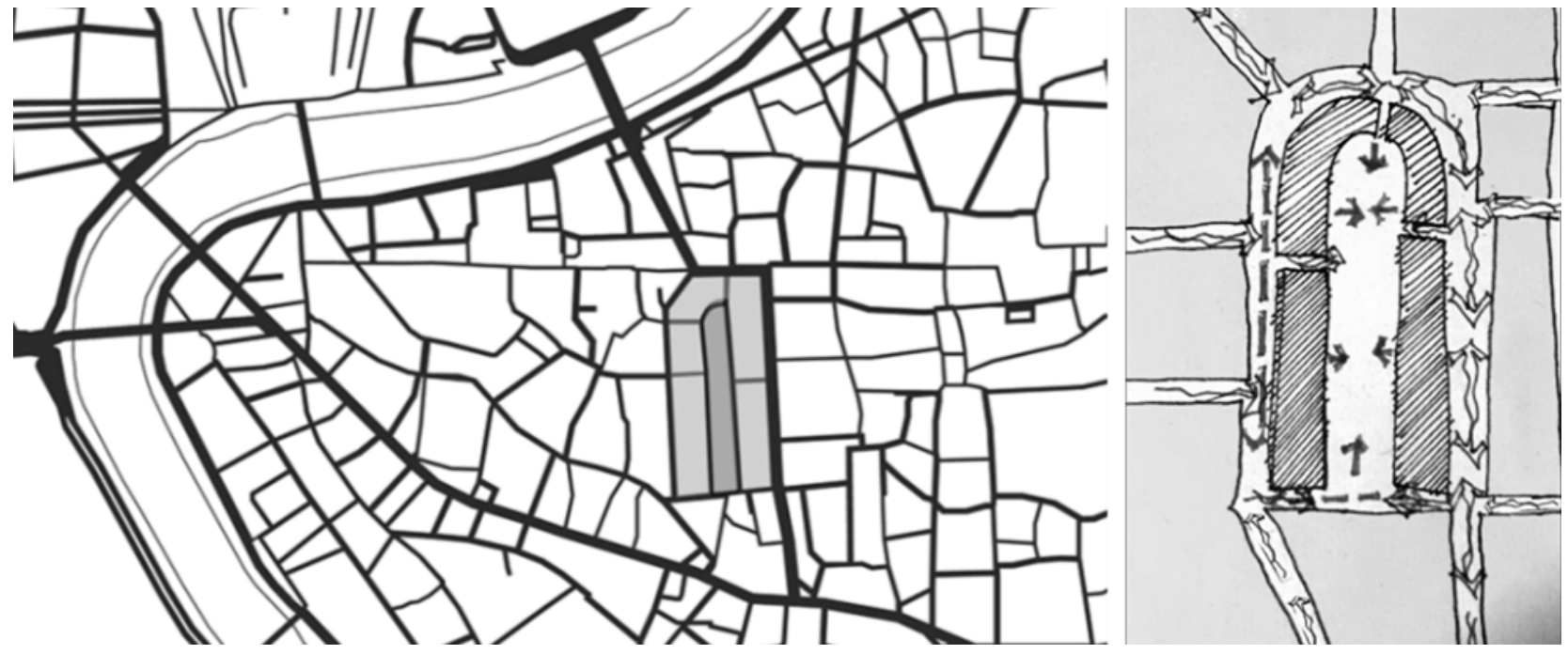

\subsection{Navona Meydanı Yaya ve Taşıı Noktaları}

Navona Meydanı'nın çeperinde taşıt trafiği yer alırken meydanda yaya odaklı bir erişim bulunmaktadır. Meydandaki yoğun yaya güzergâhı, önemli kanal mekânlara bağlanan girişlerden başlamakta olup meydandaki anıtsal yapıların etrafında yoğunlaşmaktadır. Meydanı sarmalayan yeme-içme mekânları ve bu mekânların yarı açık alanları yayaların yoğun olarak kullandığı oturma alanları olmaktadır. Ayrıca meydanda bulunan kentsel mobilyalar ve çeşmelerin parapetleri de kentsel kullanıcının oturma alanları olarak karşımıza çıkmaktadır.

Şekil 9. Navona Meydanı Diyagramları 

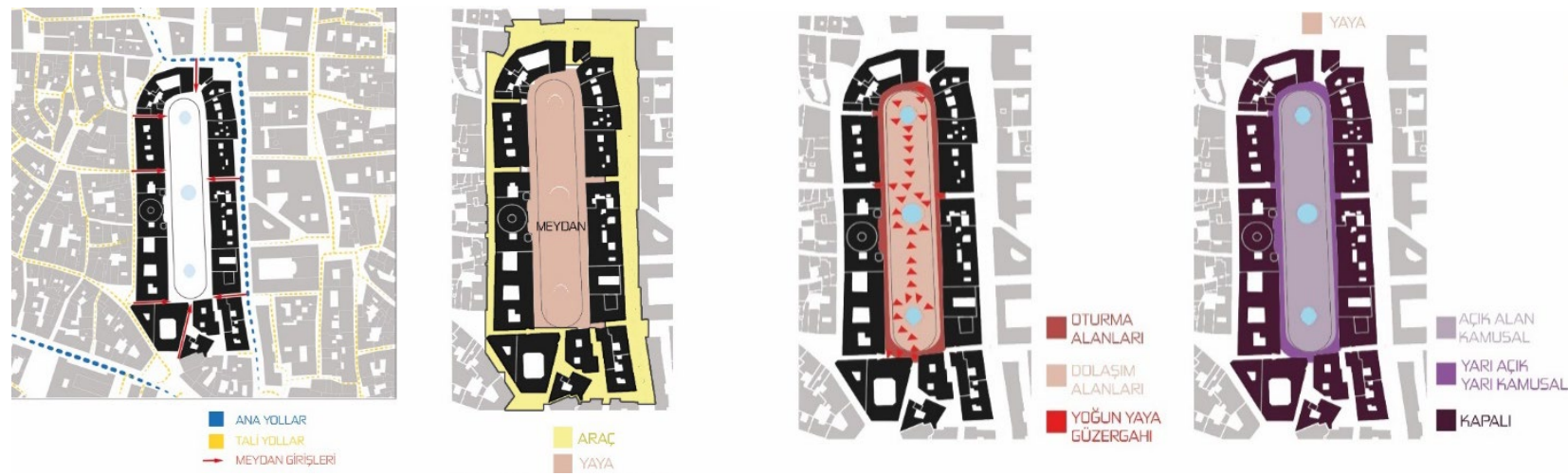

\subsection{Navona Meydanı Çevresindeki Yapılar}

Navona Meydanı'nı çevreleyen yapılar,Roma'nın mimari kimliğini yansıtmakla birlikte Roma'nın kamusal alanlarının kendine özgü özelliklerini de özetlemektedir. Meydanı çevreleyen önemli yapılar Tablo 1'de incelenmiştir:

Tab1. Navona Meydan'ıÇevresindeki Yapılar

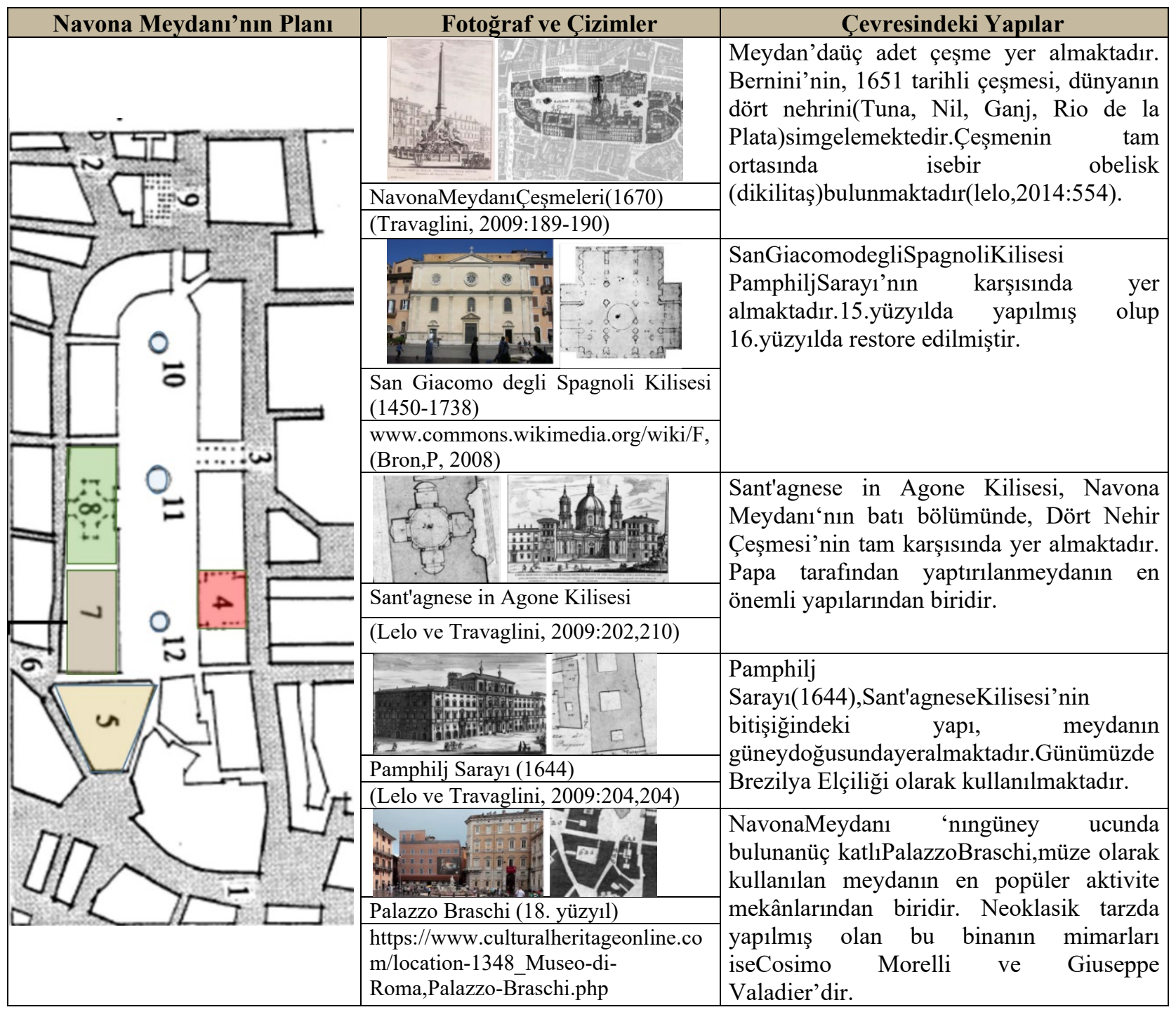




\subsection{Navona Meydanı’nın Biçimsel Özellikleri}

Navona Meydanı'nı çevreleyen yapılar meydanda kuşatılmışlık hissini arttırmak da iken meydanın sahip olduğu form, en, boy, yükseklik ilişkileri baskın meydan özelliği taşımaktadır. Meydanın kuzeyinde, güneyinde ve merkezinde inşa edilen çeşmeler uzun bir eksene sahip olan Navona Meydanı'nı dört alt alana bölmektedir (Atalay, 2010, 200). Böylece kullanıcıların mekânda duraksaması ve vakit geçirmesi sağlanmıştır. Ching bu yaklaşımı şu şekilde ifade etmiş̧ir: "biçimi olan alanlarda uzun eksen boyunca bir devinim olmakla beraber, kareye yakın alanda ise daha durağan ve içinden geçilecek bir mekân yerine, içinde kalınacak bir mekân etkisi hissedilecektir. Uzun ve dar bir alanın uzun kenarının açık olduğu durumlarda ise mekân belirli sayıda bölgeler oluşturmak üzere alt-parçalara ayrılmaya meyilli olmaktadır (Ching, 2002)". Navona meydanı hem kapalılık etkisi hem de kullanııı algısı açısından Ching'in ifadesine iyi bir örnek oluşturmaktadır. Navona Meydanı, kuzey-güney yönünde yaklaşık $246 \mathrm{~m}$ uzunluğunda ve doğu-batı yönünde yaklaşı $54 \mathrm{~m}$ genişliğindedir (Kwon, 2016:89). Meydanın ana yapıları, Pamphilj Sarayı ve Sant'agnese in Agone Katedrali, meydanın uzun kenarında yer almaktadır. Bu nedenle meydan daha derin hissedilmekte ve kuşatılmışlık hissi artmaktadır. Merkezde bulunan Dört Nehir Çeşmesi, kullanıcıyı merkeze çekmekte ve kuzeyinde bulunan Sant'agnese in agone Katedrali'ne bakış açısı sağlamaktadır (Özcan, 2009, 225). Çeşmenin merkez ekseni St. Annese in Agone Katedrali'nin girişinin ana ekseninin yaklaşık 18m kuzeyindedir. Bu konum ve uzaklık meydanda çeşme ile katedralin cephesi arasındaki görsel çatışmanın oluşmaması ve kentsel kullanıcının her iki mimari unsuru da algılaması için yapılan kasıtlı bir plandır (Kwon, 2016:90). Sekiz farklı girişi bulunan meydanın her girişi farklı bir görüş açısı sunmaktadır. Örneğin Meydanın doğusundaki Pantheon'dan gelen yaya yoğunluğunun yüksek olduğu girişte,ana bakışı Pamphilj Sarayı ve Agone Katedrali oluşturmaktadır. Dolayısıyla Navona Meydanı kentsel kullanıcının algısına etki eden; oran, ölçek, denge vb. tasarı unsurları düşünülerek tasarlanmıştır.

Şekil 10. Navona Meydanı Giriş, Ölçü ve Bakış Açısı (Kaynak: Yazarlar, Kwon, 2016:90)

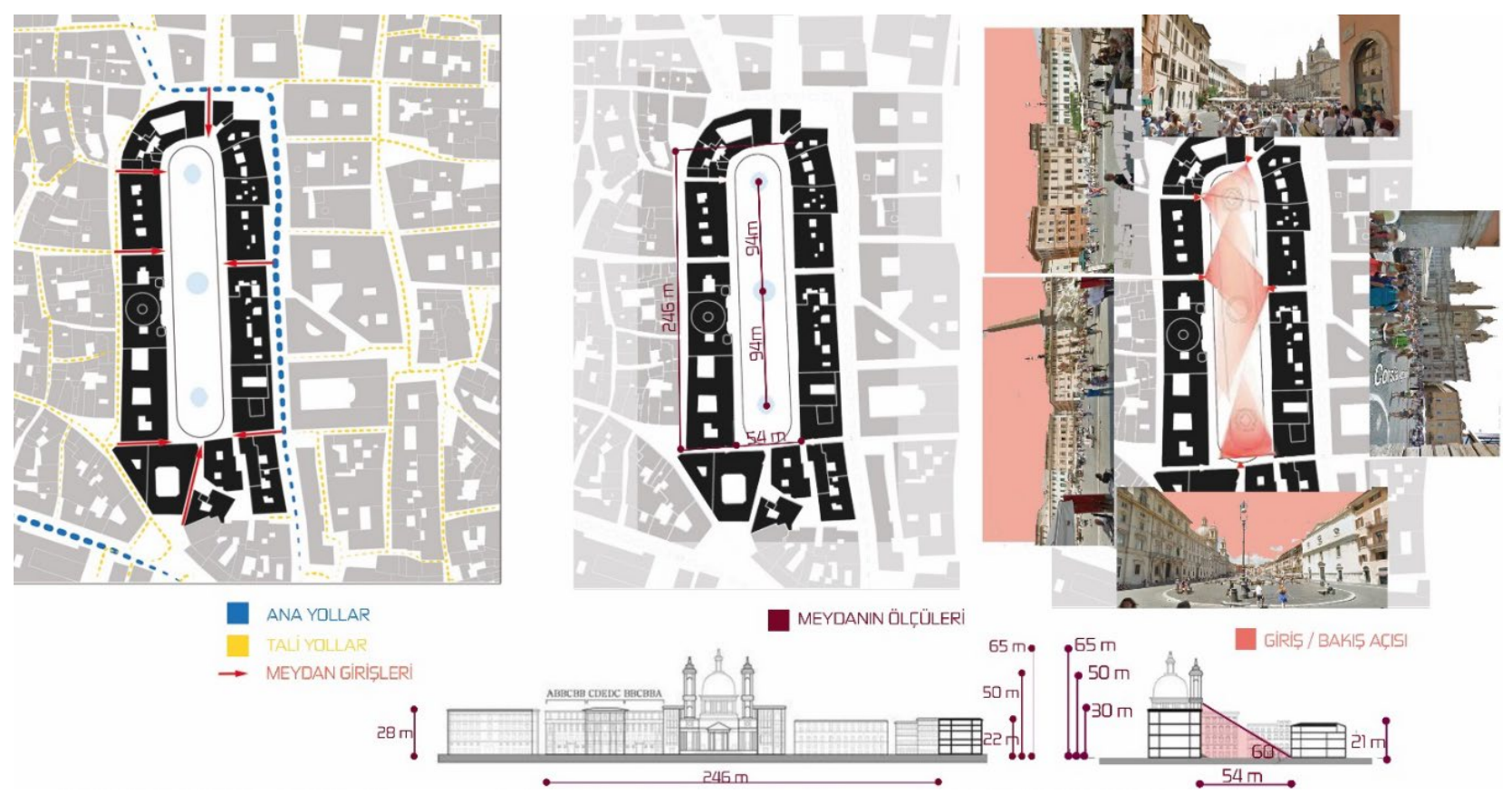

\subsection{Navona Meydanı Mimari Malzeme, Renk ve Doku özellikleri}

Navona Meydanı'nında yapı malzemesi olarak 'taş, tüf, traverten, mermer, granit, kireçtaşı, kaymak taşı, bazalt, porfir ve Roma betonu gibi doğal malzemeler kullanılmışır. Meydan da kullanılan yer, konut, aydınlatma, kent mobilyası malzemeleri de doğaldır" (Özcan, 2009: 247). Beş ve altı katlı benzer bina yükseklikleri, sıva kaplama malzemeleri ve aynı büyüklükteki dikdörtgen pencereler meydanı çevreleyen bina cephelerinde homojenlik göstermektedir. $\mathrm{Bu}$ homojenlik cephedeki pencerelerin ritmini değiştirerek monotonluktan kurtarılmıştır. Binaların rengi de aynı tonda veya bir bütün olarak birbiri ile uyumlu renklerin bir araya gelmesinden oluşmaktadır (Kwon, 2016:90). 


\subsection{Navona Meydanı Sembol ve Odakları}

Navona Meydanı'nın odak noktasını; meydanın kuzeyinde, güneyinde ve merkezinde bulunan çeşme ve heykeller oluşturmaktadır. Bu odak noktalarındaki sanat eserleri aynı zamanda meydanın sembollerini oluşturmaktadır. Çeşmeler, sanatsal değeri yüksek olan heykellerin görsel olarak da daha iyi algılanmasını sağlarken aynı zamanda su sesinin işitsel algısı da insanları bu noktalara çekmektedir. Atalay'a göre, "Modern uygulamalarda da su faktörü hem dekorasyon unsuruhem de etkinlik alanı olarak kullanılmaktadır. Yukarı doğru fışkıran su dikey bir denge unsuru olarak da mimari mekâna değer katabilir. Ayrıca serinlik ve ses özelliği ile hoş duygular uyandırmakta çok etkili olmaktadır. Yalnızca önceki uygulamalarda geometrik etkilerinin yanı sıra taşıdığı anlamlar ve içerik bakımından zenginliğini bu dönemde algılamak oldukça güçtür" (Atalay, 2010: 227). Neptün çeşmesi ile Fiumi ve Morro çeşmeleri arasındaki mesafe, yaklaşık 94 metredir; bu sebeple çok sayıda kullanıcı bu mekânlar da toplanabilmekte ve esnek bir şekilde meydanı kullanabilmektedir (Kwon, 2016:90).

Şekil 11. Navona Meydanı'nın Merkez ve Odaklar
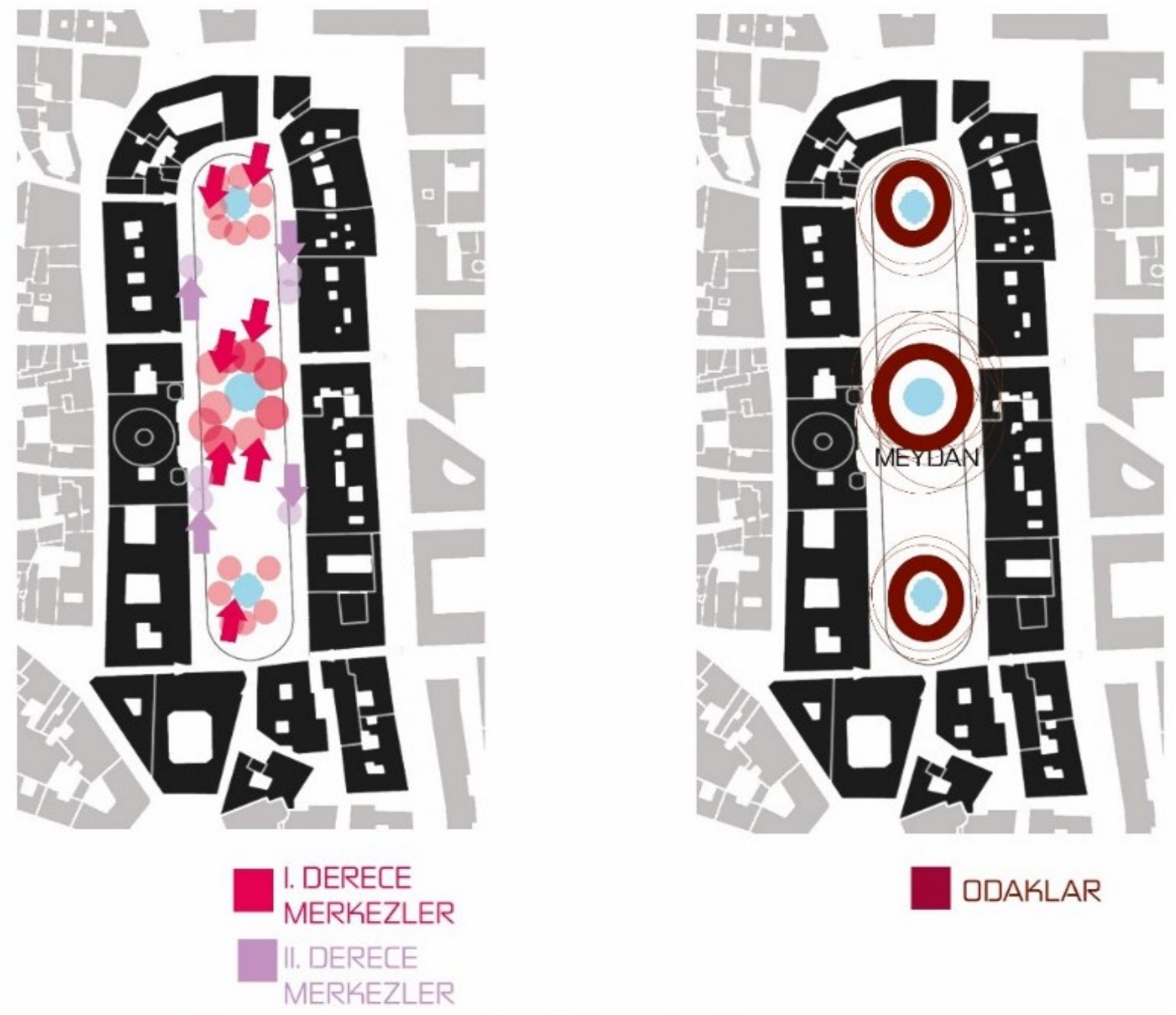


\section{Sonuç}

Tab2. Navona Meydan’1 fiziksel kalite ölçütleri

\begin{tabular}{|c|c|c|c|c|c|}
\hline Faktörler & \multicolumn{2}{|l|}{ Analiz } & Faktörler & \multicolumn{2}{|c|}{ Analiz } \\
\hline \multirow{2}{*}{$\begin{array}{c}\Xi \\
\stackrel{\Xi}{\Xi} \\
\stackrel{\Xi}{\Xi}\end{array}$} & $\begin{array}{l}\text { Toplu taşıma araçları } \\
\text { (otobüs vb.) }\end{array}$ & $\begin{array}{l}\text { Nostaljik at } \\
\text { arabasi }\end{array}$ & \multirow{2}{*}{ 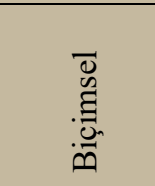 } & Mekân algısı güçlü & Yönlenme yüksek \\
\hline & $\begin{array}{l}\text { Özel araç (bisiklet, } \\
\text { metro, otomobil) }\end{array}$ & Yaya & & İnsan ölçeği & Oran \\
\hline \multirow{2}{*}{ Erişim } & \multicolumn{2}{|c|}{ Mekân içinde rahat hareket } & \multirow{2}{*}{ Kapalılık } & \multirow[t]{2}{*}{ Güçlü } & \multirow[t]{2}{*}{ Baskın } \\
\hline & \multicolumn{2}{|c|}{ Kolay yönelim ve dolaşım } & & & \\
\hline \multirow{4}{*}{ 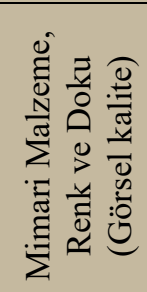 } & \multicolumn{2}{|c|}{$\begin{array}{l}\text { Görsel süreklilik, çeşitlilik } \\
\text { sağlanmaktadır. }\end{array}$} & \multirow{4}{*}{ 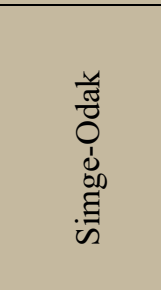 } & \multicolumn{2}{|l|}{ Çeşme } \\
\hline & \multicolumn{2}{|c|}{$\begin{array}{l}\text { Yatay ve dikey etki meydanda } \\
\text { dengelidir. }\end{array}$} & & \multicolumn{2}{|l|}{ Heykel } \\
\hline & \multicolumn{2}{|c|}{ Ritim, hiyerarşi, oran vardır } & & \multicolumn{2}{|l|}{ Obelisk } \\
\hline & \multicolumn{2}{|l|}{ Işık ve gölge } & & \multicolumn{2}{|l|}{ Kilise } \\
\hline
\end{tabular}

Navona Meydanı, Antik Roma döneminin ilk yüzyılından itibaren kalabalıkların toplandığı kentin merkezi niteliğinde bir meydandır. Günümüzde Navona Meydanı çevresinde yoğunlaşan restoranlar, kafeler vb. ticari işlevler; meydanın canlı tutulması ve sürdürülebilirliği üzerinde olumlu bir etkiye sahiptir. Navona Meydanı tarihsel süreçten günümüze kadar farklı yaş, cinsiyet ve sosyal statüdeki insanların bir araya geldiği diyalog ortamını oluşturmaktadır. Meydanın incelenen fiziksel özellikleri de bu sürdürülebilirliği desteklemektedir (Tab.2). Meydanın sosyal, doğal, tarihi ve fiziksel değerleri kente, bölgeye ve ülke ekonomisine pek çok katkı sunmaktadır. Navona Meydan’1 geçmişten günümüze kadar farklı işlevleri barındırması ve çevresine farklı binalar eklenmesine rağmen mekânsal yapısını korumuştur. Bu durum Navona Meydanı'nı özgün kılmaktadır. Dolayısıyla meydanın sahip olduğu fiziksel ve işlevsel özelliklerin korunarak kentsel belleğin sürdürülmesi ve gelecek kuşaklara aktarılması sağlanmalıdır.

Tarihi meydan açısından zengin olan ülkemizde de meydanların fiziksel ve işlevsel özellikleri kalite parametreleri kullanılarak analiz edilmeli ve mevcut potansiyellerle koruma yaklaşımları geliştirilmelidir.Özellikle İstanbul'daki tarihi meydanların niteliklerinin korunması için ulaşım, erişim, mimari malzeme, renk ve doku, biçimsel özellikler, kapalılık, simge-odak ve işlevsel faktörlerin göz önünde bulundurularak değerlendirilmesi ve gelecek kuşaklara aktarımının sağlanması önerilmektedir.

\section{Etik Standart ile Uyumluluk}

Çıkar Çatışması: Yazarlar herhangi bir çıkar çatışmasının olmadığını beyan eder.

Etik Kurul İzni: Bu çalışma için etik kurul iznine gerek olmadığını beyan ederim.

Finansal Destek: Yok

Teşekkür: Yok.

\section{KAYNAKÇA:}

Atalay, N. (2010).Kent meydanı: kamusal estetik çerçevede eleştirel bir değerlendirme, Doktora Tezi, Fen Bilimleri Enstitüsü, İstanbul Teknik Üniversitesi, İstanbul.

Ching, F.D.K., (2002).Mimarlı: biçim, mekân ve düzen, çev. S. Lökçe, YEM Yayınları, İstanbul.

Camargo, E., (1981).Piazza Navona, Harvard Square, Piccadilly Circus: a study about morphology and use, Master Thesis, Techonolgy of Institute, Federal University, Soul Brazil. 
Eyüce, Ö., (2000). Meydanlar, Ege Mimarlık Dergisi, 34, S.10-11.

Erdönmez, E., \&Abay., E (2018).Roma Popolo Meydanı bağlamında kamusal mekân kalitesinin ölçülmesi, Kent Akademisi. 11-33, S. 44-59.

Çınarı, S., (2005).Meydanlardaki tarihi değişimler ve günümüze yansımaları, İstanbul Üniversitesi Orman Fakültesi Dergisi, 55-1, S.112-121

Kwon, N., (2016). The architectural characteristics of Piazza Navona, Rome and its ecological function and role in urban environments, Journal of the Korea Institute of Ecological Architecture and Environment ,16-6, S.83-94.

Hoşkara,Ö., (2007). Anadolu- Türk kentlerindeki kentsel mekânlara -meydanlara fonksiyonel bir bakış. A. Mengi (Dü.) içinde, Kent ve Politika Antik Kentten Dünya Kentine. Ankara: İmge Kitapevi, S. 215-220

Özcan, B., (2009).Sürdürülebilir kent meydanları ve Roma Piazza Navona örneğinde incelenmesi, Yüksek Lisans Tezi, Sosyal Bilimler Enstitüsü, Hacettepe Üniversitesi, Ankara.

Şahin, A., (1996).Meydanınnitelikleri üzerine bir analiz, Yüksek Lisans Tezi, O.D.T.Ü Fen Bilimleri Enstitüsü, Ankara.

Sala, İ., (2009).Geçmişten günümüze meydan tasarımında yönetimsel farklılığın etkileri; Tiran örneği, Mimar Sinan Güzel Sanatlar Üniversitesi Fen Bilimleri Enstitüsü, Mimarlık Anabilim Dalı, Bina Bilgisi Programı, Yüksek Lisans Tezi, İstanbul.

Sennett, R. (2011).Ten ve taş (4 b.). İstanbul: Metis.

Taşçı, H., (2012).Kent meydanı ile kent kimliği ilişkisi Üsküdar Meydanı örneği, Doktora Tezi, Marmara Üniversitesi, İstanbul.

Lelo, K., \&Travaglini,.C.M, (2009).Roma tarihi atlas'ının cbs'si: m. panzeri, a. farruggia'da (19. yüzyılda) on dokuzuncu yüzyıl kadastro kaynaklarının bilgilendirilmesi, entegrasyonu ve ortak analizi için metodolojiler, Fonti, Metafonti ve CBS, bölgenin tarihi yapısının araştırılması için, Torino, 2009, S. 51-60.

Keskin, S., (2018).Modern kentlinin kentsel mekân düşlemleri: Elazığ kent meydanı önerileri. 1. Uluslararası Eğitim ve Sosyal Bilimlerde Yeni Ufuklar Kongresi Bildiriler Kitabı, 9- 11.

Yıldırım, E., (2004). İstanbul'da kent mobilyaları 'nın değerlendirilmesi Sultanahmet Meydanı örneği.Yüksek Lisans, İstanbul Teknik Üniversitesi, Fen Bilimleri Enstitüsü, İstanbul.

\section{İnternet Kaynakları:}

Bakerjian M., (2019). Walking Tour in Piazza Navona, https://www.tripsavvy.com/piazza-navona-walking-tour1547882, 04 Kasım.

Bron,P, (2008). Roma- Chiesa di San Giacomo degli Spagnoli ora Nostra Signora del Sacro Cuore, https://www.flickr.com/photos/pietbron/2794123874, 04 Kasim 2019.

Le Termi Di Costantino, http://roma.andreapollett.com/S6/roma2-03i.htm, 04 Kasım 2019.

Nostra_Signora_del_Sacro_Cuore_a_Piazza_Navona, https://romanchurches.fandom.com/wiki/Nostra_Signora_del_Sacro_Cuore_a_Piazza_Navona, 04 Kasim 2019.

Rossi, G., Fountain in Piazza Navona, https://www.wga.hu/html_m/f/falda/navona.html, 04 Kasım 2019. 